\title{
DEVELOPMENT OF WOOD GRINDING 3. FURTHER TESTING OF GRINDING MODELS
}

\author{
BRUNO LÖNNBERG \\ Pulping Technology, Åbo Akademi University, \\ Åbo, Finland \\ Corresponding author: Professor Emeritus B. Lönnberg, blonnber@abo.fi
}

Received June 7, 2021

\begin{abstract}
The study is the continuation of a sequence of works devoted to describing the mechanisms occurring during stone grinding of wood. This part was aimed at further testing of pressurised grinding of spruce wood, which was conducted under controlled laboratory conditions. Testing of the developed theoretical model for power ratio $\left(P_{\mathrm{c}} / P_{\mathrm{t}}\right)$ versus energy specific production $\left(\dot{G}_{\mathrm{w}} / P_{\mathrm{t}}\right)$ produced linears for data representing constant wood moisture content. However, the linears showed almost identical results for fresh woods, and also for drier wood, e.g. wood containing saturated fibres and air-dried wood, although one would expect some differences due to the widely varying constant moisture, from $65 \%$ to $15 \%$ moisture content.

Simplification of the model resulted in $\left(c_{\mathrm{w}}+X c_{\mathrm{m}}\right) \Delta T_{\mathrm{p}-\mathrm{w}} \approx P_{\mathrm{t}} / \dot{G}_{\mathrm{w}}$, and it led to specific linears, when the members as such were correlated between themselves at several constant wood moisture contents. The results were briefly as follows. Increasing wood feed rate $-0.7,1.0$ and $1.3 \mathrm{~mm} / \mathrm{s}$ - decreased the specific energy requirement, while increased stone surface speed -20 and $30 \mathrm{~m} / \mathrm{s}$ - increased it. The left-hand member or the " $X$-factor" as named in this context, correlated with the right-hand member or the specific energy requirement and resulted in declining linears. The lower the wood moisture content - 65, 58, 44, 28 and 15\% - the smaller was the linear declination, and also the difference due to stone surface speed.

The application of an energy balance could be useful in searching for a working wood grinding model. Such a model would enable critical examination of wood grinding conditions. Also, it would help understanding the mechanism of various factors, such as grinding parameters, wood properties and stone burr and sharpness. It seems that there are factors that are not known well enough for further development of grinding. Shower water flow and temperature affect the stone surface temperature as known, but their significance for the energy balance or grinding mechanism are not known. Also, the thin film of pulp slurry between the stone surface and the heat activated wood layer is evidently a significant factor that is connected to the local energy transfer.
\end{abstract}

Keywords: balance, energy, grinding, heat, mechanism, modelling, power, temperature, wood

\section{INTRODUCTION}

Mechanical fiberising of wood has been concentrated for years on improvement of pulp fibre length and fibrillation. Disc refining of wood chips has been largely investigated, as log grinding research reduced. Refiners could be easily pressurised and that led to high temperatures within the wood and accordingly, to sufficient lignin softening and superior fiberising. Hence, long fibres were produced, which are well suited for paperboard and also various papers subsequent to some bleaching and beating. However, refiner mechanical pulps require more energy in fiberising and their yield is much lower than that of grinder pulps.
Accordingly, increasing energy and increasing wood prices would favour stone grinding of wood $\operatorname{logs}-\mathrm{a}$ process that has been used for more than a century. Grinding converts most of the wood to paper making fibres and fines, and as it requires less energy than disc refining, it could be a competitive process in the future. There should be enough knowledge about grinding and refining to enable smart development of the mechanical pulping processes. Hence, log grinding could probably be even further developed.

Attempts to describe stone grinding of wood included initial correlations of the power ratio and energy specific production that resulted in linears. 


\section{BRUNO LÖNNBERG}

As based on an energy balance, the mathematically derived model seemed acceptable for such an evaluation. However, the linears did not follow logical expectations, as fresh wood samples seemed to act in the same way, and the wood samples of a moisture content close to fibre saturation acted, among themselves, as well in the same way, but clearly different from the fresh wood samples.

\section{RESULTS AND DICUSSION}

\section{Modification of the energy balance model}

The energy balance derived ${ }^{1}$ for a theoretical wood grinding case resulted in model (4):

$\left(P_{\mathrm{c}} / P_{\mathrm{t}}\right)+1 \approx\left(c_{\mathrm{w}}+X c_{\mathrm{m}}\right) \cdot \Delta T_{\mathrm{p}-\mathrm{w}} \cdot\left(\dot{G}_{\mathrm{w}} / P_{\mathrm{t}}\right)$

Model (4) was tested initially by correlation of the power ratio $P_{\mathrm{c}} / P_{\mathrm{t}}$ and the energy specific production $\dot{G}_{\mathrm{w}} / P_{\mathrm{t}}$. However, since $P_{\mathrm{c}} / P_{\mathrm{t}}<<1$, the energy balance could also be expressed as follows, without a significant mistake:

$1 \approx\left(c_{\mathrm{w}}+X c_{\mathrm{m}}\right) \cdot \Delta T_{\mathrm{p}-\mathrm{w}} \cdot\left(\dot{G}_{\mathrm{w}} / P_{\mathrm{t}}\right)$

or $1 /\left[\left(\dot{G}_{\mathrm{w}} / P_{\mathrm{t}}\right)\right]=P_{\mathrm{t}} / \dot{G}_{\mathrm{w}} \approx\left(c_{\mathrm{w}}+X c_{\mathrm{m}}\right) \cdot \Delta T_{\mathrm{p}-\mathrm{w}}(6)$

The left- and right-hand members were correlated to check whether they react to changes in wood moisture content. For this purpose, it was suggested that the heat generated because of some mechanical breakage would, more or less, increase the temperature of the wood and moisture in it or around it. As a first step, the heat transfer was supposed to be complete, which, probably, is not the case in reality, since the rate of fibre release is very high. If considering one specific fibre cell column of a common wood matrix, the fibre release may be $20-40$ fibres in one second.

\section{Grinding data applied}

Data presented by Riissanen ${ }^{2}$ were applied for computing the members of the energy balance model (6) and the results obtained are visible in Figure 1. The members are not digitally identical as suggested by the energy balance, but the picture is anyhow worth a closer look. The wood moisture contents resulted in different specific energy levels. At high moisture contents representing fresh wood, the stone surface speed affected the location of linears. The stone speed of $30 \mathrm{~m} / \mathrm{s}$ resulted in a clearly higher specific energy requirement than that of $20 \mathrm{~m} / \mathrm{s}$. However, higher wood feed rate decreased it at both stone speed levels, but increased simultaneously the expression $\left(c_{\mathrm{w}}+X c_{\mathrm{m}}\right) \cdot \Delta T_{\mathrm{p}-\mathrm{w}}$, named the " $X$ factor" that resulted in declining linears. This pattern was repeated at all wood moisture contents studied, but at moisture contents close to fibre wall saturation ( $28 \%$ moisture content) and air-dried wood, the difference between the stone surface speeds studied was practically negligible, as was the declination of linears.

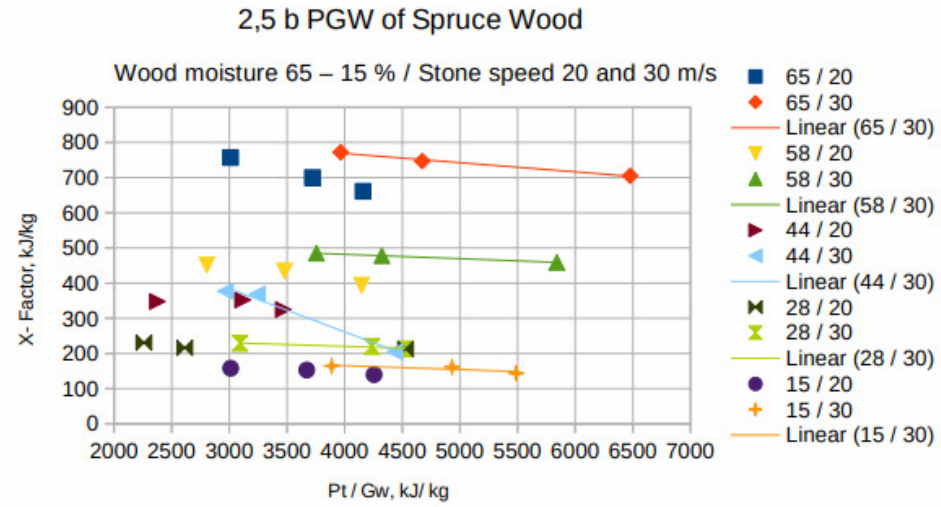

Figure 1: " $X$ factor", identical to the expression $\left(c_{\mathrm{w}}+X c_{\mathrm{m}}\right) \cdot \Delta T_{\mathrm{p}-\mathrm{w}}$ presented as a function of the specific energy requirement $P_{\mathrm{t}} / \dot{G}_{\mathrm{w}}$ in pressurised grinding of fully water impregnated spruce wood (Picea abies C.), fresh wood and slightly dried wood (44\% moisture), as well as wood having saturated fibre walls and air-dried wood (15\% moisture); stone surface speed: 20 and $30 \mathrm{~m} / \mathrm{s}$, and wood feed rates: $0.7,1.0$ and $1.3 \mathrm{~mm} / \mathrm{s}$. Data by Riissanen ${ }^{2}$

The evident digital imbalance of model (6) needs to be investigated for clarification of the reasons. One might be the shower water temperature and flow that were uncertain.
Lucander ${ }^{3}$ paid attention to the shower water in laboratory grindings of spruce and its significance for the temperature of the pulp slurry between the heat excited wood and the colder stone surface. In 
fact, it is apparently the less investigated area of wood grinding, and it might provide some clarification of the digital imbalance of the present energy balance model.

\section{CONCLUSION}

By considering the wood moisture content, an energy balance of mechanical wood grinding used to produce papermaking fibres might help describe and understand the true wood grinding mechanisms. The present attempt to do so produced linears in a graph " $X$ factor" versus specific energy requirement. High wood moisture content produced declining linears at a high level in the graph, as low moisture gave less declining linears at a low level. Higher stone surface speed ( $30 \mathrm{~m} / \mathrm{s}$ compared to $20 \mathrm{~m} / \mathrm{s}$ ) always resulted in higher energy requirements. Higher wood feed rate again decreased it, but increased simultaneously the " $X$ factor". At moisture contents close to fibre wall saturation, the stone surface speeds gave nearly identical linears.

Generally speaking, wood grinding technology still seems to be insufficiently known, at least concerning the mechanisms between the heat excited wood and the shower water cooled stone surface. The conditions of this zone, such as pressure, temperature and wood viscoelastic behaviour, are certainly fundamental. The present energy balance was established for conditions providing that the balance area between the wood and the stone is closed in the sense that shower water has little effect after its entrance into the zone. It might be the case in industrial grinding, where the wood feeding pockets are large, but laboratory grinders have small feeding pockets. Establishing an energy balance including the shower water energy might give prerequisites of a more truthful energy balance and hence better understanding of the grinding mechanisms.

\section{REFERENCES}

1 B. Lönnberg, Cellulose Chem. Technol., 54, 49 (2020),

https://doi.org/10.35812/CelluloseChemTechnol.2020. 54.90

2 M. Riissanen, M. Tech. Thesis, Åbo Akademi University, Faculty of Chemical Technology, Åbo, 2002, 70 p., conducted by Prof. B. Lönnberg, Laboratory of Pulping Technology, https://www.abo.fi/en/fct-masters-theses/

3 L. Salmén, M. Lucander and E. Härkönen, in "Mechanical Pulping", $2^{\text {nd }}$ updated ed., edited by B. Lönnberg, book series "Papermaking Science and Technology", Publisher Paper Engineer's Association/Paperi ja Puu Oy, 2009, Chapter 4, p. 3667 